\title{
SORÇÃO DE COBRE E MANGANÊS POR BACTÉRIAS RIZOSFÉRICAS DO TRIGO
}

\author{
COPPER AND MANGANESE SORPTION BY WHEAT RHIZOSPHERIC BACTERIA
}

\author{
Marcio Voss ${ }^{1}$ Robert Wayne Stefen Phillip Thomas ${ }^{2}$
}

\section{RESUMO}

\begin{abstract}
A bioacumulação de metais por microrganismos se deve principalmente a fenômenos de superfície, ocorrendo adsorção, de forma estequiométrica, com os radicais aniônicos dos envoltórios celulares, seguido ou não de precipitação dos metais. Para estudar condicionantes da sorção de metais por bactérias vivas, quantificou-se o $\mathrm{Cu}^{2+}$ e $\mathrm{Mn}^{2+}$ retirados por um Bacillus sp. e uma Pseudomonas sp., isolados da rizosfera de trigo, de uma solução de cloreto dos metais, determinando-se a quantidade de metal restante no sobrenadante, após centrifugação. Usou-se delineamento experimental inteiramente casualizado, com três repetições. Ensaiaram-se efeito dos teores de $\mathrm{Cu}^{2+}$ e $\mathrm{Mn}^{2+}$, do $\mathrm{pH}$ e do tempo de crescimento bacteriano. $\mathrm{O}$ Bacillus sorveu mais $\mathrm{Cu}^{2+}$ e $\mathrm{Mn}^{2+}$ do que Pseudomonas. em todas as concentrações desses metais. A sorção de $\mathrm{Cu}^{2+}$ por ambas as bactérias apresentou maiores incrementos do que $\mathrm{Mn}^{2+}$ com aumento dos teores desses metais na solução. A alteração do pH 5,0 para 3,0 diminuiu a sorção dos dois metais. Com o tempo de cultivo de 90 horas a Pseudomonas apresentou maior sorção de cobre e de manganês do que no tempo de 16 horas. Os resultados obtidos assemelham-se aos fenomenos de troca de cátions em colóides.
\end{abstract}

Palavras-chave: adsorção, $p H$, glicocálix, concentração de metais, tempo de incubação.

\section{SUMMARY}

The metals bioaccumulation in microganisms is mainly a result of superficial phenomena, occurring adsoption, in a stoychometric way, with the anionic radicals of cellular walls followed or not by precipitation of metals. To study the sorption of metals by live bacteria, the $\mathrm{Cu}^{2+}$ and $\mathrm{Mn}^{2+}$ taken up by a Bacillus sp. and a Pseudomonas sp., were quantified isolated from weath rizosphere, from a cloride solution of metals resting in the supernatant, after centrifugation. A completely randomized experimental design was used, with 3 repetitions. The effect of $\mathrm{Cu}^{2+}$ and $\mathrm{Mn}^{2+}$ contents, $\mathrm{pH}$ and time of bacterial growth were tested. Bacillus sorbed more $\mathrm{Cu}^{2+}$ and $\mathrm{Mn}^{2+}$ than Pseudomonas in all concentrations of those metals. $\mathrm{Cu}^{2+}$ sorption by both bacteria showed more increase than $\mathrm{Mn}^{2+}$ with rising those metals content in the solution. Alteration of $\mathrm{pH}$ from 5,0 to 3,0 reduced the metal sorption. With 90 hour cultivation time, Pseudomonas showed more $\mathrm{Cu}^{2+}$ and $\mathrm{Mn}^{2+}$ sorption than with 16 hour cultivation time. The results agree with the colloids cations exchange phenomena.

Key words: adsorption, glycocalix, metals content, $p H$ effects, incubation time.

\section{INTRODUÇÃO}

A sorção (adsorção e/ou absorção) de metais por microrganismos tem despertado a atenção de pesquisadores pela capacidade superior da biomassa microbiana em comparação com outros sorventes inorgânicos e orgânicos (KUREK $\boldsymbol{e t}$ al, 1982). Estudos têm demonstrado que, na maior parte dos casos, a bioacumulação de metais por microorganismos se deve a fenômenos de superfície (adsorção e/ou precipitação) (BEVERIDGE, 1989; COLLINS \& STOTZKY, 1992; SHOKOHIFARD et al., 1990;).

As bactérias têm ponto isoelétrico entre pH 2 e 4, possuindo caráter aniônico em condições comuns de pH de solo e de água (HARDEN \& HARRIS, 1953). As cargas negativas são originadas da ionização dos radicais carboxílicos, fosfáticos, hidroxílicos e sulfidrílicos encontrados nos polímeros da parede microbiana (BEVERIDGE, 1989).

As bactérias gram-positivas, como as do gênero Bacillus, têm sua parede composta por peptideoglicanos, com ou sem ácidos teicóicos e

\footnotetext{
${ }^{1}$ Engenheiro Agrônomo, Doutor, Pesquisador da Embrapa Trigo, CP 451, 99001-970, Passo Fundo, RS. E-mail: voss@ cnpt.embrapa.br. Autor para correspondência.

${ }^{2}$ Microbiólogo, PhD., Rua Marcos T. Ferreira, 419, 94415-350. Viamão, RS.

Recebido para publicação em 03.10.00. Aprovado em 07.03.01
} 
teicourônicos. As bactérias gram-negativas, como as do gênero Pseudomonas, têm cerca de $20 \%$ menos peptideoglicanos mas possuem membrana externa com fosfolipídeos e lipopolissacarídeos. Proteínas e lipoproteínas ocorrem em ambos os tipos de bactérias (NEIDHARDT $\boldsymbol{e t}$ al., 1990).

Eventualmente, conforme o tipo de metal e do microorganismo, a sorção supera o número de cargas, com ocorrência de precipitados, de tal forma que se tem desenvolvido filtros biológicos para retirar metais pesados de soluções (BEVERIDGE \& MURRAY, 1976)

Os estudos demonstrativos de adsorção e precipitação de metais em bactérias tem sido conduzidos com paredes ou membranas externas de bactérias desintegradas, como descrito em BEVERIDGE \& MURRAY (1976) e BEVERIDGE \& KOVAL (1981). Para estudar condicionantes da sorção de metais por bactérias vivas, quantificou-se a sorção de $\mathrm{Cu}^{2+}$ e $\mathrm{Mn}^{2+}$ por uma bactéria gramnegativa e outra gram positiva, isoladas de rizosfera de trigo, para utilização em estudos subseqüentes de interação plantas e microorganismos, em relação a cobre e manganês (VOSS \& THOMAS, 1998).

\section{MATERIAL E MÉTODOS}

As atividades descritas a seguir foram desenvolvidas na Faculdade de Agronomia da UFRGS (Porto Alegre, RS) e na Embrapa Trigo (Passo Fundo, RS), entre 1991 e 1992.

As bactérias utilizadas foram isoladas de rizoplano de trigo, e pertencem aos gêneros Bacillus e Pseudomonas. A primeira, gram-positiva, cuja origem e identificação se encontra descrita em PERONDI (1992), foi cedida por Wilmar Cório da Luz. A segunda, gram-negativa, foi obtida em Passo Fundo por Marcio Voss (VOSS, 1993).

Para a preservação das bactérias em geladeira, empregou-se meio com Triptona da Difco, (10g), Soitona da Difco (2g) e Agar da Merck (12g), com pH 6,5, com renovação a cada três meses. Para o preparo da biomassa microbiana utilizou-se o mesmo meio, sem agar.

Todos os utensílios, após limpeza com detergente e ácido sulfúrico concentrado, foram lavados com $\mathrm{HCL} 0,1 \mathrm{~N}$ e enxaguados com três passagens de água destilada e deionizada.

Soluções estoques de $5 \mathrm{mM}$ foram preparadas isoladamente para cada cátion dos compostos $\mathrm{CuCl}_{2} .2 \mathrm{H}_{2} \mathrm{O}$ e $\mathrm{MnCl}_{2} \cdot 4 \mathrm{H}_{2} \mathrm{O}$, com água destilada e deionizada. $\mathrm{O}$ pH das soluções e curvas de cobre e de manganês foram ajustados para valores entre 5,0 e 5,5, através da adição de $\mathrm{HCl}$ diluído. Exceto no ensaio de doses de metais, a dose usada foi de $0,500 \mathrm{mM}$, que após a adição de um $\mathrm{m} \ell$ de biomassa bacteriana ou de água, forneceu uma dose inicial de $0,450 \mathrm{mM}$.

A biomassa bacteriana utilizada nos ensaios foi obtida por incubação em caldo triptonasoitona, com 200 rev. $\mathrm{min}^{-1}$, em agitador orbital, a partir de inóculo com 0,5 unidades de absorbância a $400 \mathrm{~nm}$, usando-se $0,1 \mathrm{~m} \ell$ para cada $50 \mathrm{~m} \ell$ de caldo. A temperatura ambiental foi de $25+/-1^{\circ} \mathrm{C}$ e $\mathrm{o}$ período de crescimento das bactérias foi de 16 horas, exceto em um tratamento em que se cultivaram as bactérias por 90 horas. A biomassa microbiana foi retirada do caldo de cultura através de centrifugação a 4200 rev. $\mathrm{min}^{-1}$, por 15 minutos, à temperatura de $10\left(^{+} .1\right) \mathrm{C}$.

Após eliminação do sobrenadante, a biomassa precipitada foi ressuspensa, com ajuda de bastão de vidro, em $\mathrm{H}_{2} \mathrm{O}$ destilada e deionizada, $\mathrm{pH}$ 5,5 , em volume equivalente ao da primeira centrifugação. Esta suspensão foi centrifugada nas condições da centrifugação descrita anteriormente. Eliminou-se o sobrenadante, ressuspendeu-se o precipitado em $\mathrm{H}_{2} \mathrm{O}$ e centrifugou-se novamente. Desta feita, o precipitado da biomassa foi ressuspenso com $\mathrm{H}_{2} \mathrm{O}$, pH 5,5, em volume de apenas 1/10 do caldo inicial. Para determinar a massa de bactérias utilizada nos tratamentos, separou-se $10 \mathrm{~m} \ell$ dessa ressuspensão e colocou-se a secar por $72 \mathrm{~h}$ a $60^{\circ} \mathrm{C}$.

A aplicação dos tratamentos foi feita em tubos de ensaio com $10 \mathrm{~m} \ell$ de solução com um dos metais. Colocou-se $\operatorname{lm} \ell$ da ressuspensão de bactérias, contendo aproximadamente $10 \mathrm{mg}$ de matéria seca de bactérias. $\mathrm{O} \mathrm{pH}$ foi previamente ajustado com $\mathrm{HCl}$ diluído, no intuito de manter o $\mathrm{pH}$ entre 5,0 e 5,5 durante a centrifugação. A centrifugação, à 4200 rev.min ${ }^{-1}$, e à temperatura de $10\left(^{+} 1\right)^{\circ} \mathrm{C}$, durou 15 minutos. Incluindo o tempo até a tomada da amostra, o processo tomou 20 minutos.

Após a centrifugação, retirou-se $1 \mathrm{~m} \ell$ do sobrenadante, e dilui-se com $10 \mathrm{~m} \ell$ de $\mathrm{H}_{2} 0$ destilada e deionizada, para leitura, por absorção atômica, dos metais que permaneceram após a aplicação dos tratamentos. Um controle sem bactérias foi feito, promovendo a mesma diluição de $\operatorname{lm} \ell$ da solução metálica. Os resultados foram comparados com as determinações das concentrações das solução metálicas usadas. A diferença entre as determinações dos metais nos tratamentos e no controle sem bactérias foi atribuída à retirada dos metais pelas bactérias. 
A presença ou ausência do glicocálix nas células bacterianas foi determinada em microscópio ótico usando-se tinta nanquim como contraste. A verificação de exopolissacarídeos nos sobrenadantes das centrifugações para o preparo da suspensão bacteriana concentrada foi determinada conforme descrito em NIETSCKE (1992).

Usou-se o delineamento inteiramente casualizado, com três repetições, e as médias foram comparadas pelo teste de Tukey a $1 \%$. Os ensaios compararam efeito de teores de $\mathrm{Cu}^{2+}$ e $\mathrm{Mn}^{2+}$, do $\mathrm{pH}$ e do tempo de crescimento das bactérias na sorção dos cátions por Bacillus ou por Pseudomonas. Os tratamentos estão discriminados nas tabelas dos resultados.

Os ensaios de efeito do $\mathrm{pH}$ e do tempo de cultivo foram realizados utilizando-se a mesma ressuspensão bacteriana obtida após 16 horas de crescimento das bactérias. Como foram conduzidos simultaneamente, os dados de sorção, no tempo de 20 minutos e com a concentração de $0,450 \mathrm{mM}$ e pH 5,0 , aparecem repetidos nas tabelas 2 e 3 .

\section{RESULTADOS E DISCUSSÃO}

Efeito da quantidade de $\mathrm{Cu}^{2+}$ e $\mathrm{Mn}^{2+}$ na sua sorção por Bacillus sp. e por Pseudomonas sp

O contato da biomassa bacteriana, com solução de $\mathrm{Cu}^{2+}$ e $\mathrm{Mn}^{2+}$, a pH 5,0, por 20 minutos, proporcionou os seguintes resultados (Tabela 1): Bacillus sp. sorveu mais $\mathrm{Cu}^{2+}$ e $\mathrm{Mn}^{2+}$ do que Pseudomonas sp. em todas as concentrações e $\mathrm{Cu}^{2+}$ foi mais sorvido do que $\mathrm{Mn}^{2+}$, por ambas as bactérias, formando a seqüência Bacillus $+\mathrm{Cu}>$ Pseudomonas $+\mathrm{Cu}>$ Bacillus $+\mathrm{Mn}>$ Pseudomonas $+\mathrm{Mn}$. A preferência por $\mathrm{Cu}^{2+}$ também foi observada por

Tabela 1 - Sorção $\left(\mu \mathrm{mol} \mathrm{g} \mathrm{g}^{-1}\right)$ de $\mathrm{Cu}^{2}$ e $\mathrm{Mn}^{2+}$ por biomassa de Bacillus sp. e Pseudomonas sp., em três teores iniciais desses cátions. Média de 3 repetições.

\begin{tabular}{|c|c|c|c|c|}
\hline \multirow{3}{*}{$\begin{array}{l}\text { Teores } \\
\text { do metal } \\
(\mathrm{mM})\end{array}$} & \multicolumn{4}{|c|}{ Sorção $\left(\mu \mathrm{mol} \mathrm{g}{ }^{-1}\right)$} \\
\hline & \multicolumn{2}{|r|}{$\mathrm{Cu}^{2+}$} & \multicolumn{2}{|r|}{$\mathrm{Mn}^{2+}$} \\
\hline & Bacillus & Pseudomonas & Bacillus & Pseudomonas \\
\hline 0,225 & $174 \mathrm{cA}^{1}$ & $141 \mathrm{c} \mathrm{B}$ & $94 \mathrm{a} \mathrm{C}$ & $59 \mathrm{a} D$ \\
\hline 0,450 & $251 \mathrm{~b} \mathrm{~A}$ & 195 b B & $100 \mathrm{a} \mathrm{C}$ & 71a D \\
\hline 0,675 & $304 \mathrm{a} A$ & $234 \mathrm{a} \quad \mathrm{B}$ & $118 \mathrm{a} \mathrm{C}$ & $77 \mathrm{a} D$ \\
\hline
\end{tabular}

${ }^{1}$ Letras minúsculas para comparação na coluna e maiúsculas, na linha. Médias seguidas pela mesma letra não diferem entre si em nível de $1 \%$ de probabilidade de erro pelo teste de Tukey.
BEVERIDGE \& MURRAY (1976), quando o biossorvente era Bacillus subtilis M 1032. Quando paredes da bactéria gram-negativa Escherichia coli foram empregadas como sorventes, (BEVERIDGE \& KOVAL, 1981), $\mathrm{Mn}^{2+}$ foi sorvido em maior quantidade do que $\mathrm{Cu}^{2+}$. Este último trabalho contrasta com os resultados aqui obtidos com a também gram-negativa Pseudomonas sp., evidenciando a dificuldade de generalizações. A ocorrência de adsorção diferenciada, conforme as características do metal e do tipo de sorvente, é atribuída, por FERRIS \& BEVERIDGE (1986) a diferenças termodinamicamente favoráveis entre a energia de hidratação do íon e a energia final de ligação nos radicais dessas paredes.

A sorção de $\mathrm{Cu}^{2+}$ cresceu com o aumento da concentração desses metais como pode ser visto na mesma tabela. Embora a mesma tendência se tenha observado na sorção de $\mathrm{Mn}^{2+}$, esta não apresentou diferença significativa estatisticamente entre os tratamentos. A afinidade de paredes de bactérias e fungos por metais como função aparente da concentração inicial da solução foi estudada por MULLEN et al. (1989 e 1992), que sugeriram o logarítmo decimal da quantidade de metal sorvido em micromol $\mathrm{g}^{-1}$ de concentração de equilíbrio a $1 \mathrm{mM}$ como índice dessa afinidade. Aplicando-se a equação da isoterma de adsorção de Freundlich aos dados do presente ensaio, o $\log \mathrm{K}$ de Bacillus $+\mathrm{Cu}$, Pseudomonas $+\mathrm{Cu}$ e Pseudomonas $+\mathrm{Mn}$, foi, respectivamente, $1,669,1,523$ e 1,297, com $\mathrm{R}^{2}$ de 94\%, 84\% e 92\%. Bacillus $+\mathrm{Mn}$ apresentou um $\mathrm{R}^{2}$ de $55,38 \%$.

A adequação dos dados a uma equação empregada para descrever fenômenos de superfície indica que grande parte das sorções observadas no presente ensaio ocorreram na parede das bactérias.

Efeito do pH da suspensão bacteriana na sorção de $\mathrm{Cu}^{2+}$ e $\mathrm{Mn}^{2+}$

A alteração do $\mathrm{pH}$ de 5,0 para 3,0 diminuiu a quantidade de metais sorvidos (Tabela 2). Esse decréscimo foi maior para $\mathrm{Mn}^{2+}$ em Bacillus sp. (90,65\%), menor para $\mathrm{Cu}^{2+}$ em Pseudomonas sp. $(55,05 \%)$ e intermediário para cobre em Bacillus $(64,20 \%)$ e para manganês em Pseudomonas (67,50\%). Esses percentuais indicam que a maior parte dos metais estava adsorvido à superfície das bactérias. 
Tabela 2 - Efeito do pH na sorção $\left(\mu \mathrm{mol} \mathrm{g}{ }^{-1}\right)$ de $\mathrm{Cu}^{2+} \mathrm{e} \mathrm{Mn}^{2+}$ com teor inicial de 0,450mM por biomassa de Bacillus sp. e Pseudomonas sp. Média de 3 repetições.

\begin{tabular}{|c|c|c|c|c|}
\hline \multirow{3}{*}{$\mathrm{pH}$} & \multicolumn{4}{|c|}{ Sorção $\left(\mu \mathrm{mol} \mathrm{g}{ }^{-1}\right)$} \\
\hline & \multicolumn{2}{|r|}{$\mathrm{Cu}^{2+}$} & \multicolumn{2}{|r|}{$\mathrm{Mn}^{2+}$} \\
\hline & Bacillus & Pseudomonas & Bacillus & Pseudomonas \\
\hline 3 & $96 \mathrm{bA}$ & $89 \mathrm{~b} \mathrm{~A}$ & $13 \mathrm{~b} \mathrm{C}$ & $27 \mathrm{~b} \mathrm{~B}$ \\
\hline 5 & $268 \mathrm{a} A$ & $198 \mathrm{a} \quad \mathrm{B}$ & 139a C & $83 a \quad D$ \\
\hline C.V. $=5,47 \%$ & & & & \\
\hline
\end{tabular}

Letras minúsculas para comparação na coluna, e maiúsculas, na linha. Médias seguidas pela mesma letra não diferem entre si em nível de $1 \%$ de probabilidade de erro pelo teste de Tukey.

As diferenças encontradas na adsorção pelas bactérias utilizadas, cujas paredes celulares são muito contrastantes, estão de acordo com resultados encontrados na literatura, como os de COLLINS \& STOTZKY, (1992), mostrando que o pI varia em função da espécie bacteriana e do metal presente. Estes autores encontraram pI menor para Bacillus sp. ( $\mathrm{pI}=1,3)$ do que para Pseudomonas aeruginosa $(\mathrm{pI}=2,5)$, com $\mathrm{CuCl}_{2}$ na solução. Com $\mathrm{MgCl}_{2}$, os pI respectivos passaram a 3,6 e 2,0. Como os compostos orgânicos ionogênicos têm pI diferente, a alteração do $\mathrm{pH}$, através da adição ou consumo de $\mathrm{H}^{+}$, não afeta todos os radicais ao mesmo tempo. Por exemplo, próximo a valores de $\mathrm{pH} 3$, os fosfatos ainda estão carregados negativamente (TOBIN $\boldsymbol{e t}$ al. 1984).

No presente ensaio, Bacillus sp. mostrou maior dessorção de $\mathrm{Mn}^{2+}$, do que de $\mathrm{Cu}^{2+}$, e o resultado pode advir em parte de um $\mathrm{pI}$ menor da bactéria com $\mathrm{Cu}^{2+}$ do que com $\mathrm{Mn}^{2+}$. O comportamento da sorção neste ensaio adequa-se ao esperado de fenômenos de troca iônica.

\section{Efeito do tempo de crescimento bacteriano na sorção de $\mathrm{Cu}^{2+}$ ou $\mathrm{Mn}^{2+}$}

Detectou-se a presença de glicocálix em Pseudomonas sp., com 90 horas e não com 16 horas de incubação no caldo de cultura. Em Bacillus sp. não apareceu o glicocálix em nenhuma das idades das culturas. Nos sobrenadantes de ambas as bactérias não apareceram exopolissacarídeos.

Em Bacillus sp. a sorção de $\mathrm{Cu}^{2+}$ e $\mathrm{Mn}^{2+}$ não aumentou, quando $\mathrm{o}$ tempo de crescimento das células passou de 16 para 90 horas. Mas, no isolado de Pseudomonas sp., chegou a $65 \%$ o acréscimo de $\mathrm{Cu}^{2+}$ e $111 \%$ o de $\mathrm{Mn}^{2+}$ sorvido pela sua biomassa após $90 \mathrm{~h}$ de crescimento, em comparação com a quantidade sorvida com $16 \mathrm{~h}$ de crescimento (Tabela 3 ).

Com esse acréscimo, Pseudomonas superou Bacillus na sorção de cobre e de manganês, alterando a série liotrófica observada nos ensaios anteriores.

Os polissacarídeos, que compõem o glicocálix em Pseudomonas (SUNTHERLAND, 1972), aumentaram a quantidade de radicais ionogênicos, incrementando, assim, a sorção de $\mathrm{Cu}^{2+}$ e $\mathrm{Mn}^{2+}$. Por outro lado, a ausência de glicocálix em Bacillus sp., não criou condições sortivas diferentes para a biomassa de ambos os períodos de crescimento.

Os resultados obtidos no presente ensaio são indicativos de fenômenos de adsorção.

\section{CONCLUSÕES}

A adsorção predomina sobre outros fenômenos de sorção de cobre e de manganês observada em um isolado de Bacillus e outro de Pseudomonas.

Com a formação de glicocálix, o isolado de Pseudomonas supera o de Bacillus na sorção de cobre e de manganês.

A adsorção de cobre nas bactérias é mais afetada pela concentração do metal do que a de manganês.

\section{AGRADECIMENTOS}

Os autores agradecem o apoio financeiro da Fapergs e as facilidades fornecidas pela UFRGS e Embrapa Trigo.

Tabela 3 - Efeito da idade da cultura na sorção de $\mathrm{Cu}^{2+}$ e $\mathrm{Mn}^{2+}$ por biomassa de Bacillus sp. e Pseudomonas sp., ( $\left.\mu \mathrm{mol} \mathrm{g}{ }^{-1}\right)$ com solução inicial de 0,450mM dos metais. Média de 3 repetições.

\begin{tabular}{|c|c|c|c|c|}
\hline \multirow{3}{*}{$\begin{array}{l}\text { Idade } \\
\text { da } \\
\text { cultura }\end{array}$} & \multicolumn{4}{|c|}{ Sorção $\left(\mu \mathrm{mol} \mathrm{g}{ }^{-1}\right)$} \\
\hline & \multicolumn{2}{|r|}{$\mathrm{Cu}^{2+}$} & \multicolumn{2}{|r|}{$\mathrm{Mn}^{2+}$} \\
\hline & Bacillus & Pseudomonas & Bacillus & Pseudomonas \\
\hline $16 \mathrm{~h}$ & $268 \mathrm{aA}^{1}$ & 198 b B & $139 a \mathrm{C}$ & $83 \mathrm{~b} \quad \mathrm{D}$ \\
\hline $90 \mathrm{~h}$ & $254 \mathrm{a} \mathrm{B}$ & $325 \mathrm{a} A$ & 140a D & $175 \mathrm{a} \quad \mathrm{C}$ \\
\hline C.V. $=5,62 \%$ & & & & \\
\hline
\end{tabular}

${ }^{1}$ Letras minúsculas, para comparação na coluna e maiúsculas, na linha. Médias seguidas pela mesma letra não diferem entre si em nível de $1 \%$ de probabilidade de erro pelo teste de Tukey. 


\section{REFERÊNCIAS BIBLIOGRÁFICAS}

BEVERIDGE, T.J. Role of cellular design in bacteria-metal acumulation and mineralization. Annual Review of Microbiology, Palo Alto, v.43, p.147-171, 1989.

BEVERIDGE, T.J., KOVAL, S.F. Binding of metals to cell envelops of Escherichia coli M-12. Applied and Environmental Microbiology, New York, v.42, n.2, p.325$335,1981$.

BEVERIDGE, T.J., MURRAY, R.G.E. Uptake and retention of metals by cell walls of Bacillus subtilis. Journal of Bacteriology, New York, v.127, n.3, p.1508-1518, 1976.

COLLINS, Y.E., STOTZKY, G. Heavy metal alter the electrokinetic properties of bacteria, yeast and clay minerals. Applied and Environmental Microbiology, New York, v.58, n.5, p.1592-1600, 1992

FERRIS, F.G., BEVERIDGE, T.J. Physicochemical roles of soluble metal cations in the outer membrane of Escherichia coli K-12. Canadian Journal of Microbiology, Ottawa, v.32, p.594-601, 1986.

HARDEN, V.P., HARRIS, J.P. Isoeletric point of bacterial cells. Journal of Bacteriology, New York, v.65, p.198-202, 1953.

KUREK, E., CZABAN, J., BOLLAG, J.M. Sorption of cadmium by microorganisms in competition with others soil constituents. Applied and Environmental Microbiology, New York, v.43, n.5, p.1011-1015, 1982.

MULLEN, M.D., WOLF, D.C., BEVERIDGE, T.J., et al. Sorption of heavy metals by soil fungi Aspergillus niger and Mucor rouxii. Soil Biology and Biochemistry Elmsford, v. 24, n.2, p.129-135, 1989.

MULLEN, M.D., WOLF, D.C., FERRIS, F.G., et al Bacterial sorption of heavy metals. Applied and Environmental microbiolgy, New York, v.55, p.3143-3149, 1992.
NEIDHART, F.C., INGRAHAM, J.L., SCHAECUTER, M. Physiology of the bacterial cell: a molecular approach. Massachusets : Sinauer, 1990. 506p.

NIETSCKE, M. Produção de goma xantana por diferentes isolados de Xanthomonas campestris. Porto Alegre, 1992. 115p. Dissertação (Mestrado em Microbiologia Agrícola e do Ambiente) - Universidade Federal do Rio Grande do Sul, 1992.

PERONDI, N.L. Controle microbiológico da giberela do trigo. Porto Alegre, 1992. 114p. Disseertação (Mestrado em Microbiologia Agrícola e do Ambiente) - Universidade Federal do Rio Grande do Sul, 1992.

SHOKOHIFARD, G., HAMADA, R., SAKAGAMI, K. Ion(Na)-holding capacity of microbial biomass under saline conditions. Soil Biology and Biochemistry, Elmsford, v.22, n.7, p.993-994, 1990.

SUNTHERLAND, J.W. Bacterial exopolissaccharide. Advances in Microbial Physiology, San Diego, v.8, p.143-213. 1972.

TOBIN, J.M., COOPER, D.G., NEUFELD, R.J. Uptake of metal ions by Rhizopus arrhizus biomass. Applied and Environmental Microbiology, New York, v.47, n.4, p.821824, 1984.

VOSS, M. Sorção de cobre e manganês por bactérias rizosféricas de trigo (Triticum aestivum L.). Porto Alegre, 1993. 104p. Tese (Doutorado em Ciência do Solo) Universidade Federal do Rio Grande do Sul, 1993.

VOSS, M., THOMAS, R.W.S.P. Redução da absorção de cobre e manganês em solução por trigo infectado com Pseudomonas sp. Pesquisa Agropecuária Brasileira, Brasília, v.33, n.5, p.755-760, 1998.

Ciência Rural, v. 31, n. 6, 2001. 